\title{
Prematurity: Epidemiological Profile and Risk Factors for Prematurity at the CHU Marrakech
}

\author{
Fatima Zahra Mouad1,2*, Fatiha Bennaoui ${ }^{1,2}$, Nadia El Idrissi Slitine ${ }^{1,2}$, \\ Fadl Mrabih Rabou Maoulainine ${ }^{1,2}$ \\ ${ }^{1}$ Neonatal Intensive Care Unit, CHU Mohammed VI, Marrakech, Morocco \\ ${ }^{2}$ Child Health and Development Research Team, Faculty of Medicine, Cadi Ayyad University, Marrakech, Morocco \\ Email: ${ }^{\star f z m o u a d @ o t m a i l . f r ~}$
}

How to cite this paper: Mouad, F.Z., Bennaoui, F., Slitine, N. El I. and Maoulainine, F.M.R. (2021) Prematurity: Epidemiological Profile and Risk Factors for Prematurity at the CHU Marrakech. Open Access Library Journal, 8: e7530.

https://doi.org/10.4236/oalib.1107530

Received: May 17, 2021

Accepted: August 16, 2021

Published: August 19, 2021

Copyright $\odot 2021$ by author(s) and Open Access Library Inc.

This work is licensed under the Creative Commons Attribution International License (CC BY 4.0).

http://creativecommons.org/licenses/by/4.0/

\begin{abstract}
Prematurity is the leading cause of neonatal mortality and morbidity. Objective: To study the epidemiological aspects and the etiological factors of prematurity. Material and Methods: A retrospective study about the newborn with prematurity and hospitalized in the neonatal and neonatal resuscitation department of the Mohammed VI university hospital during the period was from January 2019 to December 2019. Results: 585 newborns were collected including 110 premature newborns (18.8\%). The average gestational age was 30.4 weeks, with a predominance of the age group between 28 weeks and 31.6 weeks (36\%), a male predominance was noted (65\%). Cesarean in $32.5 \%$ of cases. The low socio-economic level is reported in $68.2 \%$ of cases, the low level of education in $60 \%$ of cases, $55.4 \%$ of mothers live in rural areas. Pregnancies were only well followed in $38.1 \%$. The main causes of prematurity: maternal-fetal infections in $30 \%$ of cases, the medical decision in $23 \%$ of cases, and twin pregnancy in $20 \%$ of cases. Premature rupture of the membranes was responsible for $15 \%$ of the cases. No cause was detected in $12 \%$ of cases. Respiratory distress, asphyxia and prematurity were the main causes of transfer. The associated pathologies were distress respiratory in $40 \%$ of cases, maternal-fetal infection in $30 \%$ of cases, hypotrophy in $20 \%$ of cases, and jaundice in $8 \%$ of cases. Death occurred in $40 \%$ of cases. Conclusion: Several etiological factors associated with prematurity were identified. Tackling these factors is an effective way to prevent prematurity in our low-income countries, the medical decision in $23 \%$ of cases, and twin pregnancy in $20 \%$ of cases. Premature rupture of the membranes was responsible for $15 \%$ of the cases. No cause was detected in $12 \%$ of cases. Respiratory distress, asphyxia and prematurity were the main causes of transfer. The associated pathologies were distress respiratory in $40 \%$ of cases, maternal-fetal infection in $30 \%$ of cases, hypotrophy in $20 \%$ of cases, and jaundice in $8 \%$ of cases. Death occurred in
\end{abstract}


$40 \%$ of cases.

\section{Subject Areas}

Pediatrics Neonatology

\section{Keywords}

Prematurity, Epidemiology, Morocco

\section{Introduction}

According to the World Health Organization (WHO), prematurity is defined as birth occurring before 37 completed weeks of amenorrhea, i.e. before the 259th day from the 1st day of the last menstruation, but at least 22 weeks, and this, whatever the weight but at least $500 \mathrm{~g}$ [1]. We usually distinguish late prematurity (births between 34 and 36 weeks old), moderate prematurity (32 to 33 weeks old), extreme prematurity ( 28 to 31 weeks old) and very high prematurity ( $<28$ weeks) [2]. Prematurity remains the main cause of neonatal mortality in both developed and developing countries [3]. The pathologies that cause these newborns to die can also lead to severe lifelong disability in those who survive. A Study of Current Data on the Prematurity: Epidemiological, Etiological, Physiopathological, therapeutic ... is an essential or even essential element to answer the questions and requirements of obstetricians, neonatologists, doctors, parents and decision-makers in order to deal with a pathological entity that goes far beyond the medical framework and sanitary. We therefore want this study to take stock of the epidemiological aspects, and the main risk factors of prematurity in a Moroccan maternity hospital.

\section{Material and Methods}

The medical records of premature infants admitted to the neonatal and neonatal resuscitation service of the CHU VI of Marrakech with a diagnosis of prematurity in the hospital, between January 2019 and December 2019 were reviewed retrospectively. The following variables were examined from their files: gestational age, mode of delivery, anthropometric data, APGAR score, trophicity, neonatal complications, mortality and causes of death. In the mother, we studied the socio-demographic data, the gyneco-obstetrical history, and the pathologies occurring during pregnancy.

\section{Results}

We retained 110 premature newborns over 1 year. During our study period, 585 newborns were hospitalized, a frequency of $18.8 \%$. The population was predominantly male, 71 versus 39 , or a sex ratio was 1.8 (Figure 1 ).

The term was known in $77.2 \%$ of cases, and the most common means of pre- 
cision was the date of the last period (60\%). The mean gestational age was 30.4 weeks, with a slight predominance of the age between 28 weeks and 31.6 weeks (36\%).

Extremely prematurity and extremely prematurity represented $2 \%$ and $38 \%$ of the population respectively as shown Figure 2 .

The age of the mothers varied from 18 to 45 years with an average of $28.7 \pm 5$ years, primiparity was found with respective rates of $38.1 \%$. The socio-economic level was considered low in $68.2 \%$ of cases, the low level of education in $60 \%$ of cases. Residence in rural areas represented $55.4 \%$ of percentage against $45 \%$ in urban areas. 4 admitted were from single mothers, i.e. a percentage of $3.6 \%$. Pregnancies were only well followed in 38,1 , and consanguinity was found in $16.3 \%$ of cases (Table 1 ).

Among the gyneco-obstetric history, and the medical history detected during pregnancy, several of them were associated with the onset of prematurity. They were genitourinary infections (30\%), arterial hypertension (hypertension) (20\%), pre-eclampsia (12\%), threat of premature delivery (PAD) (15\%), cervico-isthmic open bite (5\%), isolated hemorrhages and gestational diabetes (5\%).

The average birth weight was $1800 \mathrm{~g}$ [ $900 \mathrm{~g}-2100 \mathrm{~g}$ ], 20\% of premature babies were hypotrophic. The Apgar score was below 7 at the 1st minute and at the 5th minute in 34.54 and $10 \%$ of cases respectively (38 and 10 cases). The causes of prematurity are dominated by infectious causes $30 \%$, ovular foeto-placental causes $34 \%$ of cases, unexplained prematurity in $12 \%$ of cases. Morbidities during

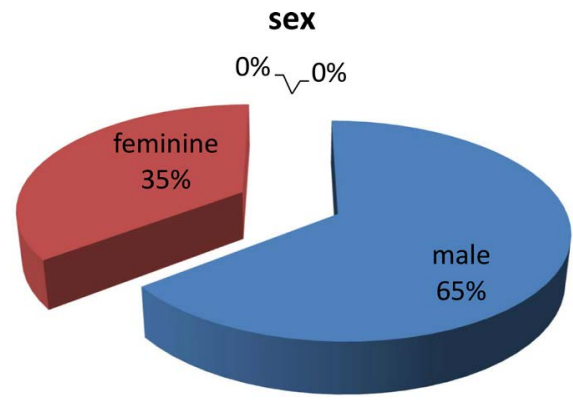

Figure 1. Distribution of patients by sex.

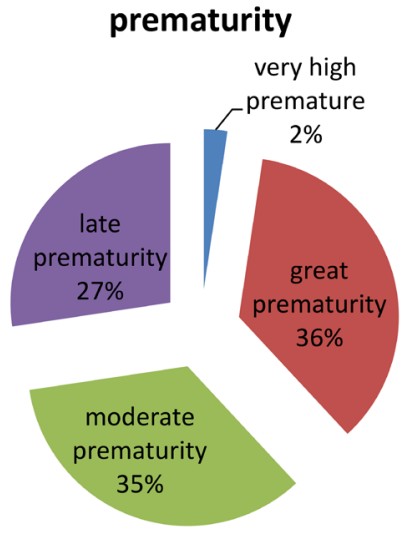

Figure 2. Distribution according to the classification of prematurity. 
Table 1. Distribution according to maternal characteristics.

\begin{tabular}{|c|c|c|c|}
\hline & & Number & percentage \\
\hline \multirow[t]{3}{*}{ Age } & $<18$ Years & 6 & 5.4 \\
\hline & Between 18 and 34 Years Old & 84 & 76.3 \\
\hline & $>$ Or $=35$ Years & 20 & 18.1 \\
\hline \multirow[t]{3}{*}{ Parity } & 1 & 42 & 38.1 \\
\hline & $>1$ and $<4$ & 44 & 40 \\
\hline & $\geq 4$ & 24 & 21.9 \\
\hline \multirow[t]{3}{*}{ Socio-economic level } & Low & 75 & 68.2 \\
\hline & Way & 35 & 31.8 \\
\hline & High & 0 & 0 \\
\hline \multirow[t]{4}{*}{ Level of education } & Never attended school & 66 & 60 \\
\hline & Primary & 39 & 35.5 \\
\hline & Secondary & 4 & 3.6 \\
\hline & University & 1 & 0.9 \\
\hline \multirow[t]{6}{*}{ Origin } & Rural & 61 & 55.4 \\
\hline & Urban & 49 & 45.5 \\
\hline & Married & 104 & 94.6 \\
\hline & Single & 4 & 3.6 \\
\hline & Widow & 1 & 0.9 \\
\hline & Divorcee & 1 & 0.9 \\
\hline \multirow[t]{3}{*}{ Pregnancy follow-up } & Well followed & 42 & 38.1 \\
\hline & Poorly followed & 28 & 25.4 \\
\hline & Not followed & 40 & 36.4 \\
\hline consanguinity & & 18 & 16.3 \\
\hline
\end{tabular}

hospitalization respiratory distress in $40 \%$ of cases, maternal-fetal infection in $30 \%$ of cases, hypotrophy in $20 \%$ of cases, jaundice in $8 \%$ of cases, and the death rate in $40 \%$ of cases. Among the causes of death, INC occupies 1st place with $56 \%$ of cases.

\section{Discussion}

The prematurity rate varies from country to country and, within a country, from region to region. In all countries, rates are increasing, even in the most developed countries where the advancement of knowledge of risk factors and mechanisms relating to preterm labor, and the introduction of several public health and medical policies should rather lead to a reduction in rates [4]. Preterm births average $12 \%$ in poor countries compared to $9 \%$ in higher income countries [3]. In our population, it is also noticed a high rate of prematurity, which is consistent with most of the other studies [3] [4]. In our study, $65 \%$ of preterm 
infants were boys, which is consistent with most other studies [5] and the cause of male predominance is not yet fully explained [6]. We found that: the low socio-economic level, the low level of education, as well as geographic origin are important risk factors associated with preterm birth and this is consistent with other studies in the literature [7] [8] [9]. There is a correlation between primiparity and prematurity; a French study on the risk factors of prematurity, demonstrated that primiparity is a risk factor significantly linked to prematurity [10]. Our study cannot claim to confirm or deny the impact of primiparity, but its rate high of $38.1 \%$ should be taken into consideration. This work also shows that suboptimal prenatal care and monitoring of pregnancy are significantly associated with the risk of prematurity. These results are confirmed by most of the data in the literature [11] [12]. Hence the importance of insisting on improving the monitoring of pregnancies with regular monitoring of pregnancies at risk of prematurity. Maternal-fetal infections are also determining causes of prematurity [13]. Maternal-fetal infection is retained as the cause of prematurity in $30 \%$ of cases, it represents the 1st cause. These infections should be systematically detected during pregnancy [14]. The other risk factors remain dominated in our study as elsewhere by arterial hypertension (hypertension), pre-eclampsia [15] [16], obstetric factors such as the threat of preterm delivery (PAD) [17], cervico-isthmic open bite [16], isolated hemorrhages and gestational diabetes [15].

Thus, we must insist on: improving the monitoring of pregnancies with regular monitoring of pregnancies at risk of prematurity in a level III maternity; screening and treatment of the infection responsible for the majority of cases of prematurity in our series.

Insufficient monitoring of pregnancy, a factor closely linked to prematurity, results in the lack of a perinatal care system and a very strong social environment unfavorable, this is demonstrated by Blondel B. [18]. Indeed, the analysis of our results shows that the absence of pregnancy follow-up was frequently attributable to the low socioeconomic status of parturients, or their rural origin, given that the concept of pregnancy monitoring for these mothers was difficult to assimilate.

\section{Conclusion}

The low level of education, the poor follow-up of pregnancy, genitourinary infections, hypertension, pre-eclampsia, PAD, and isolated hemorrhages, are associated with an increased chance of preterm birth, while the combination of adverse socio-economic risk factors appears to have a cumulative effect on the risks of prematurity. Large retrospective and prospective studies at the national level are needed to determine the exact prevalence and other risk factors for prematurity in Morocco.

\section{Conflicts of Interest}

The authors declare no conflicts of interest. 


\section{References}

[1] Lacaze-Masmonteil, T., Zupan, V. and Dehan, M. (2000) Entry into Life ... Prematurely. Medical Sciences, 16, 345-353. https://doi.org/10.4267/10608/1653

[2] Ananth, C.V. and Vintzileos, A.M. (2006) Epidemiology of Preterm Birth and Its Clinical Subtypes. The Journal of Maternal-Fetal \& Neonatal Medicine, 19, 773-782. https://doi.org/10.1080/14767050600965882

[3] Blencowe, H., Cousens, S., Oestergaard, M., Chou, D., Moller, A.B., Narwal, R., et al. (2012) National, Regional and Worldwide Estimates of Preterm Birth. Lancet, 9, 2162-2172. https://doi.org/10.1016/S0140-6736(12)60820-4

[4] Goldenberg, R.L. and Rouse, D.J. (1998) The Prevention of Premature Birth. New England Journal of Medicine, 339, 313-320. https://doi.org/10.1056/NEJM199807303390506

[5] Zeitlin, J., Saurel-Cubizolles, M.J., De Mouzon, J., Rivera, L., Ancel, P.Y., Blondel, B., et al. (2002) Fetal Sex and Premature Birth: Are Men More at Risk? Hum Reprod, 17, 2762-2728. https://doi.org/10.1093/humrep/17.10.2762

[6] Cooperstock, M. and Campbell, J. (1996) Male Excess in Premature Infants: Interactions with Gestational Age, Race and Multiple Births. Obstetrics \& Gynecology, 88, 189-193. https://doi.org/10.1016/0029-7844(96)00106-8

[7] Torchin, H. and Ancel, P.Y. (2016) Epidemiology and Risk Factors for Prematurity. Journal de Gynécologie Obstétrique et Biologie de la Reproduction, 45, 1213-1230. https://doi.org/10.1016/j.jgyn.2016.09.013

[8] Ndiaye, O., Fall, A.L., Drame, A., Sylla, A., Gueye, M., Cisse, C.T., et al. (2006) Etiological Factors of Prematurity at the Regional Hospital Center of Ziguinchor Senegal. Bulletin de la Societe de Pathologie Exotique, 99, 113-114.

[9] Sullivan, K.M., Dean, A. and Soe, M.M. (2009) On Academics: OpenEpi: A Web-Based Epidemiologic and Statistical Calculator for Public Health. Public Health Reports, 124, 471-474. https://doi.org/10.1177/003335490912400320

[10] Foix-L'Helias, L., Ancel, P.Y. and Blondel, B. (2000) Risk Factors for Prematurity in France and Comparisons between Spontaneous Prematurity and Induced Prematurity. Journal de Gynécologie Obstétrie et Biologie de la Reproduction, 29, 55-65.

[11] Cisse, C.A.T., Tall Diaw, C., Sow, S., Bnouhoud, M., Dina, G., Martin, S.L., et al. (1998) Premature Childbirth: Epidemiology and Prognosis at the Dakar University Hospital. Journal of Obstetrics and Reproductive Biology, 27, 71-76.

[12] Slattery, M.M. and Morrison, J.J. (2002) Preterm Delivery. Lancet, 360, 1489-1497. https://doi.org/10.1016/S0140-6736(02)11476-0

[13] Pambou, O., Ntsika-Kaya, P., Ekoundzola, J.R. and Mayanda, F. (2006) Pre-Term Births at the Brazzaville CHU. Cahier dEtude et de Recherche Francophone, 16, 185-189.

[14] Roze, J.C., Muller, J.B., Baraton, L. and Cailleaux, G. (2007) Focus on Extreme Prematurity in 2007. Resuscitation, 16, 408-412. https://doi.org/10.1016/j.reaurg.2007.07.006

[15] Amri, F., Fatnassi, R., Negra, S. and Khammari, S. (2008) Management of the Premature Newborn. Journal of Paediatrics and Childcare, 21, 227-231. https://doi.org/10.1016/j.jpp.2008.04.019

[16] Ancel, P.Y. (1999) Epidemiology of Premature Rupture of Membranes. Risk Factors and Consequences in Terms of Health: Maternal, Neonatal and Early Childhood Morbidity and Mortality. Journal de Gynecologie, Obstetrique et Biologie de la Reproduction, 28, 607-625. 
[17] Balaka, B., Baeta, S., Agbere, A.D., Boko, K., Kessie, K. and Assimadi, K. (2002) Risk Factors Associated with Prematurity at Lomé University Hospital in Togo. Le Bulletin de la Société de Pathologie Exotique, 95, 280-283.

[18] Blondel, B. and Marshall, B. (1998) Poor Antenatal Care in 20 French Districts: Risk Factors and Pregnancy Outcome. Journal of Epidemiology \& Community Health, 52, 501-506. https://doi.org/10.1136/jech.52.8.501 